\title{
Glycoside Compound
}

National Cancer Institute

\section{Source}

National Cancer Institute. Glycoside Compound. NCI Thesaurus. Code C45653.

An ester containing a sugar component (glycol) and a nonsugar (aglycone) component attached via oxygen or nitrogen bond. Hydrolysis of a glycoside yields one or more sugars. 